\title{
The Use of Polyvinyl Alcohol Sponge and Cyanoacrylate Glue in the Treatment of Large and Chronic Bronchopleural Fistulae following Lung Cancer Resection
}

\author{
Paolo Battistoni $^{\mathrm{a}} \quad$ Umberto Caterino $^{\mathrm{a}} \mathrm{b}$ Sandro Batzella ${ }^{\mathrm{a}}$ Raffaele Dello lacono ${ }^{\mathrm{a}}$ \\ Gabriele Lucantoni $^{a}$ Giovanni Galluccio $^{a}$ \\ ${ }^{a}$ Thoracic Endoscopy Unit, San Camillo - Forlanini Hospital, Rome, and ${ }^{\mathrm{b} C e n t e r}$ of Thoracic Endoscopy, Monaldi Hospital, \\ Naples, Italy
}

\section{Established Facts}

- Large postoperative bronchopleural fistulae represent a challenging clinical situation for thoracic surgeons and interventional bronchoscopists.

- Currently, there is no strategy of choice.

\section{Novel Insights}

- Cyanoacrylate glues are widely used for endoscopic control of bleeding from gastric varices.

- Cyanoacrylate glues can also be an available strategy for the closure of bronchopleural fistula.

\section{Keywords}

Bronchopleural fistula · Glues and coils · Fibrin glue-coated collagen patch

\begin{abstract}
Background: Bronchopleural fistulae represent a relatively rare complication of pulmonary resection. For inoperable patients, several endoscopic procedures have been described. In the presence of large and chronic bronchopleural fistulae, persistent air leaks require a surgical therapy, while endoscopic airway stent represents a useful palliative treatment. Objective: We describe the successful closure of large and chronic bronchopleural fistulae using an expandable polyvinyl alcohol (PVA) sponge and cyanoacrylate glue. Methods: In all patients, a rigid bronchoscope was used to
\end{abstract}

\section{KARGER}

(C) 2017 S. Karger AG, Basel

E-Mail karger@karger.com

www.karger.com/res insert a small cylinder of PVA sponge within the fistula. After releasing the patch, cyanoacrylate glue was applied directly on the PVA sponge using a channel catheter. This methodology induces an expansion of the clot and the closure of the air leak. The long-term outcome of treatment was checked by flexible bronchoscopy once every month for 3 months and every 6 months until 5 years. Results: We performed endoscopic treatment in 7 consecutive patients with bronchopleural fistula ranging from 4 to $8 \mathrm{~mm}$. In 6 of 7 patients, the bronchial stump was the site of the fistula. In 1 patient, the fistula was visualized on the right wall of the distal trachea. A temporary complete occlusion of the fistula was achieved in 7 of 7 patients and a definitive result in 5 of 7 patients. Conclusions: The use of an expandable PVA sponge and cyanoacrylate glue is an available strategy for endobronchial closure of bronchopleural fistulae.

(c) 2017 S. Karger AG, Basel
Umberto Caterino

Center of Thoracic Endoscopy, Monaldi Hospital

Via Leonardo Bianchi, 1

IT-80131 Naples (Italy)

E-Mail caterinou@yahoo.it 


\section{Introduction}

The treatment of bronchopleural fistula (BPF) includes various surgical and bronchoscopic procedures. For inoperable patients, conservative endoscopic procedures are the only therapeutic option to obtain complete closure of the bronchial stump. The success of the conservative procedure depends on the site, morphology, and size of the fistula [1]. A plethora of endoscopic devices, including submucosal injection of inert or irritating substances and instillation of glues or sealants, have proven successful in small and recent BPF $[2,3]$. In large or chronic BPF, temporary fistula closure has been reported after the placement of endoscopic devices (metallic, silicone, and Amplatzer devices) or spongy calf bone [1-4]. This allows improving the patient's condition for eventual surgical intervention. Most authors agree that definitive closure of an endoscopic fistula of more than $5 \mathrm{~mm}$ represents a rarity [4].

Herein, we describe a bronchoscopic technique for closing postoperative $\mathrm{BPF}$ ranging from 4 to $8 \mathrm{~mm}$ in diameter using an expandable polyvinyl alcohol (PVA) sponge (Merocel) and cyanoacrylate glue.

\section{Materials and Methods}

This study was approved by the Institutional Review Board of San Camillo - Forlanini Hospital, Rome, Italy. Written informed consent for bronchoscopy was obtained from all patients. All consecutive patients with persistent air leaks due to large (ranging from 4 to $8 \mathrm{~mm}$ ) and chronic BPF were included in the analysis. A "chronic fistula" was defined as a postoperative complication without life-threatening event $[1,2]$. Patients with smaller air leaks treated conservatively have been described in a previous study and were excluded [5]. All the procedures were performed with a Dumon rigid bronchoscope (Efer Medical, Cedex, France) under in- travenous deep sedation with short-acting narcotics and benzodiazepines. Premedication of the oropharynx was obtained by spraying with 10 -mg aliquots of $10 \%$ lidocaine hydrochloride (Xylocaine, AstraZeneca). The patients maintained spontaneous ventilation during the entire procedure with anesthetic assistance. Before treatment, the fistula channel was deepithelialized with a cytology brush. A small cylinder of an expandable PVA sponge of the same diameter as the fistula was inserted into the fistula by means of a rigid forceps through the rigid bronchoscope. The complete occlusion of the BPF was obtained after insertion of the PVA sponge cylinder into the fistula with the distal end located in a pleural cavity and the proximal end in the stump. The PVA sponge cylinder increases its volume by $2-4$ times, acquiring an hourglass shape. This increase is obtained with fluid-activated cyanoacrylate charged through a dedicated 2-channel catheter and sprayed on the PVA sponge in order to entirely close the bronchial stump and facilitate the adhesion of the sponge to the edges of the fistula [6]. Successively, the clot, as a foreign body, induces an inflammatory reaction and granulation tissue in the following weeks. The outcome of treatment was checked by flexible bronchoscopy once a month for 3 months and every 6 months for 5 years.

\section{Results}

Seven patients with a BPF larger than $4 \mathrm{~mm}$ in diameter were treated at our institution between 2009 and 2011. All patients developed BPF after surgery for lung cancer. Patient characteristics and treatment data for the 7 patients are displayed in Table 1 . The fistulae developed 1-3 days after the resection, and the mean diameter ranged from 4 to $8 \mathrm{~mm}$. The site of the fistula was the bronchial surgical suture in 6 of 7 patients. One patient presented a tracheal fistula after $4 \mathrm{R}$ lymphadenectomy following right-lobe lobectomy. All patients were primarily managed with chest tube drainage, and antibiotic treatment was instituted in order to prevent the development of empyema. Control bronchoscopies and chest X-

Table 1. Patients' characteristics and treatment data

\begin{tabular}{|c|c|c|c|c|c|c|}
\hline $\begin{array}{l}\text { Patients' } \\
\text { sex }\end{array}$ & $\begin{array}{l}\text { Patients' age, } \\
\text { years }\end{array}$ & Disease & Etiology & $\begin{array}{l}\text { Fistula } \\
\text { size, } \mathrm{mm}\end{array}$ & $\begin{array}{l}\text { Fistula } \\
\text { closure }\end{array}$ & $\begin{array}{l}\text { Fistula } \\
\text { recurrence }\end{array}$ \\
\hline M & 60 & squamous cell carcinoma & right pneumonectomy & 4 & yes & no \\
\hline $\mathrm{F}$ & 68 & squamous cell carcinoma & lower right lobectomy & 5 & yes & no \\
\hline M & 65 & squamous cell carcinoma & right pneumonectomy & 4 & yes & no \\
\hline M & 70 & squamous cell carcinoma & lower bilobectomy & 6 & yes & no \\
\hline $\mathrm{F}$ & 60 & adenocarcinoma & lower bilobectomy & 4 & yes & yes \\
\hline M & 55 & adenocarcinoma & $\begin{array}{l}\text { 4R lymphadenectomy after upper right } \\
\text { lobectomy }\end{array}$ & 8 & yes & no \\
\hline M & 72 & squamous cell carcinoma & right pneumonectomy & 4 & yes & yes \\
\hline
\end{tabular}

The lung resection included nodal dissection, and the suture was performed with a stapling device.

PVA Sponge and Cyanoacrylate Glue in BPF after Lung Cancer
Respiration 2017;94:58-61 DOI: $10.1159 / 000477350$ 


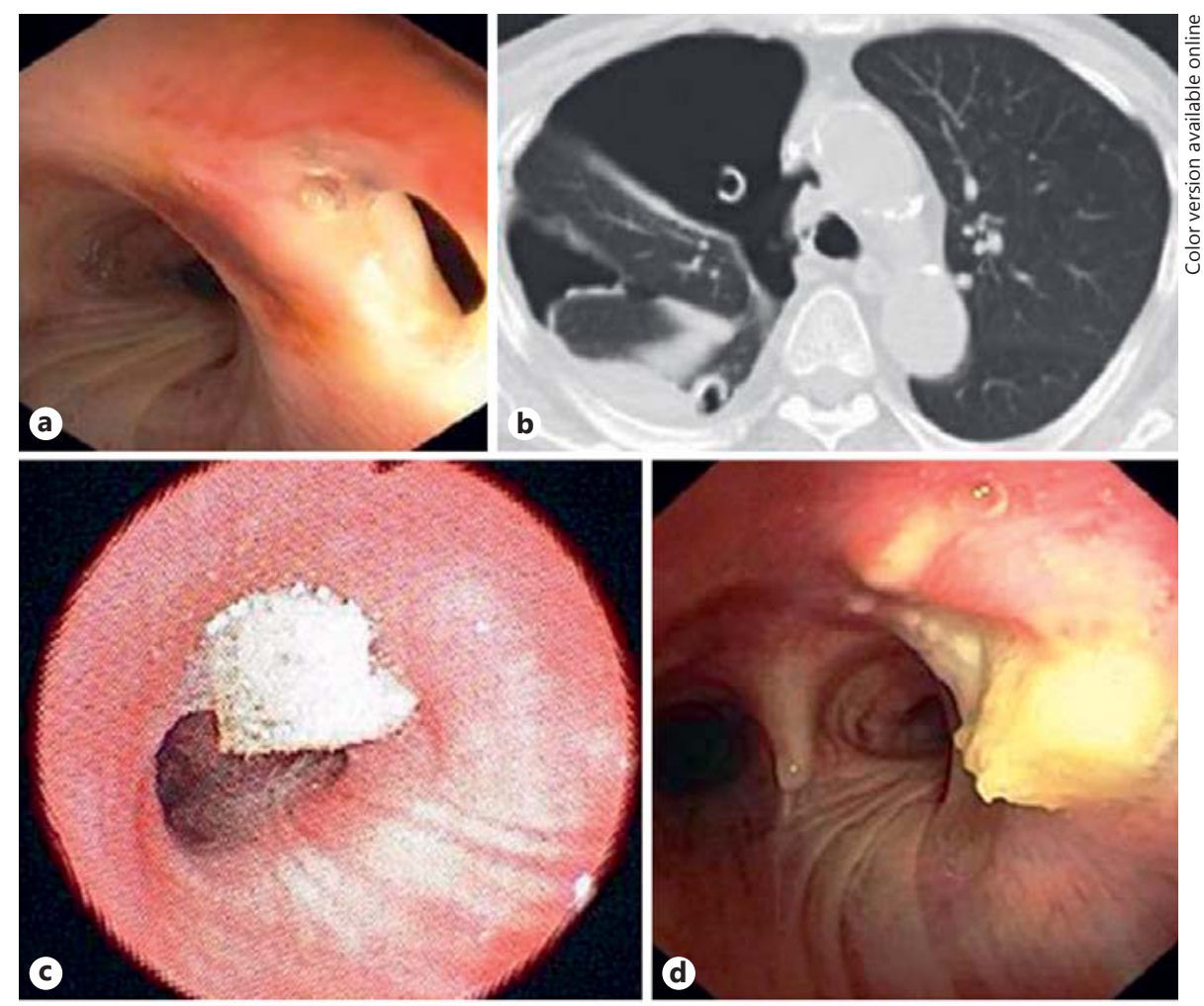

Fig. 1. a Bronchoscopic view of a fistula of the right wall of the distal trachea. $\mathbf{b}$ Chest CT scan showing right pneumothorax with intracavitary drainage. c Endoscopic view of polyvinyl alcohol sponge charged with cyanoacrylate glue. d One week later, tissue granulation completely covering the bronchopleural fistula can be observed. e, $\mathbf{f}$ Bronchoscopy and CT chest scan, 1 month later, showed complete healing of the fistula.
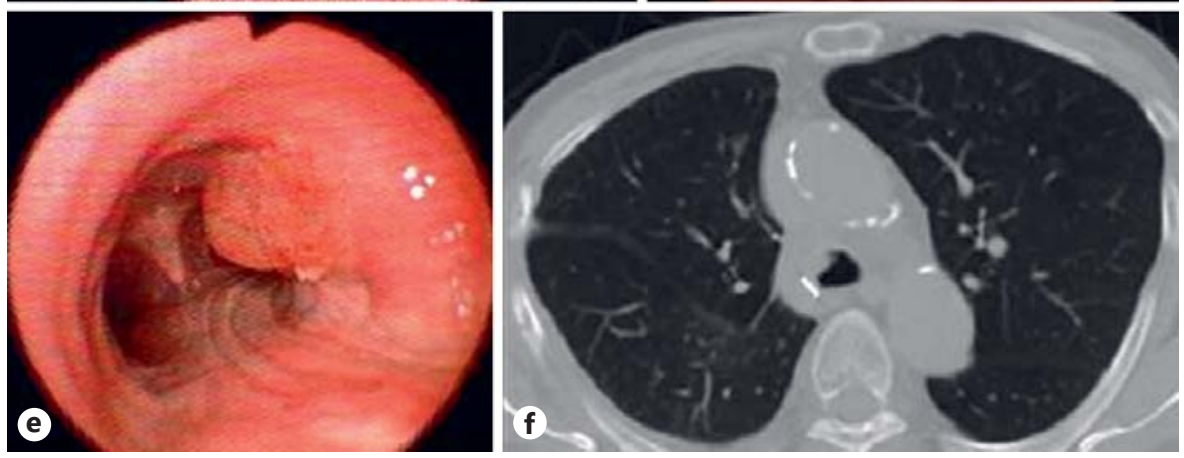

rays were performed monthly in the first 3 months and every 6 months up to 5 years after the procedure. At the end of bronchoscopic treatment, an immediate stop of air leak was observed in all patients. Granulation tissue and complete closure of the fistula were observed in 5 of 7 patients at follow-up. An example is reported in Figure 1. A relapse of the fistula was observed in 2 of 7 patients due to migration of PVA and occurred 10 days following treatment in 1 patient and 15 days following treatment in the other, respectively. The first patient (BPF after right pneumonectomy) underwent surgical repair with apposition of a muscular limb; however, he died 2 months later due to a complication of recurrent bronchial fistula, although a permanent drainage of the pleural cavity had been positioned. The second patient (BPF after bilobec- tomy) developed air leak at the surgical stump, and a completion pneumonectomy was performed with residual respiratory insufficiency. The procedure took $20 \pm 30$ min to be performed. The mean hospital stay was 2 days. No severe complications occurred after the interventional endoscopic procedures.

\section{Discussion}

$\mathrm{BPF}$ is a severe complication of lung resection surgery with significant morbidity and mortality [1]. For nonoperable patients, because of a high operative risk, an endoscopic approach may be the only alternative with curative intent of surgical repair [2]. Different bronchoscopic 
techniques depending on the size of the BPF have been reported with varying degrees of success [7]. Cyanoacrylate glues are widely used for endoscopic control of bleeding from gastric varices and for closure of fistulae or anastomotic leaks [8]. A strong bond between glue and living tissue after mechanical occlusion of the fistula determines a local reactive inflammatory response with permanent sealing of the defect $[8,9]$. Fiorelli et al. [6] reported a case series of patients with closure of small BPF using a cellulose patch and fibrin glue. In this case series, the endoscopic procedure was safe and cost-saving, and in contrast to stents or coils, the authors showed that BPF closure was obtained by a local reactive inflammatory response from the cellulose patch [6]. Although several studies report the success of sealant glues in the treatment of smaller BPF, a higher failure rate has been well documented in the presence of BPF of $5 \mathrm{~mm}$ or larger $[5,6,9$, 10]. The failure of sealing compounds in large fistulae can be due to insufficient stability in the lesion resulting in the expectoration of the plug. In recent times, an Amplatzer device has been used in larger BPF, resulting in an effective and promising method for the closure of the bronchial stump $[7,10]$.
Actually, there is no general consensus about this endoscopic procedure as a first-line option for the closure of BPF, since simultaneous use of bronchoscopy, fluoroscopy, and thoracoscopy is necessary for the correct placement of the device [7]. Furthermore, the absence of a local reaction leading to definitive healing and the high cost of the device deter from the further use of this endoscopic procedure. Successively, Dutau et al. [11] showed that airway stenting for large BPF can act as a bridge for a delayed surgery but cannot be a curative procedure. In the present paper, we showed how expandable tissues filled with fluid cyanoacrylate may represent an effective treatment in patients with chronic and larger fistulae and may be suitable for BPF different in site, shape, and size.

Obviously, we cannot draw definitive conclusions from our limited experience. Thus, our results should be corroborated by large prospective studies.

\section{Financial Disclosure and Conflicts of Interest}

There are no conflicts of interest to be declared.

\section{References}

$>1$ Lois M, Noppen M: Bronchopleural fistula. An overview of the problem with special focus on endoscopic management. Chest 2005;128: 3955-3965.

$\checkmark 2$ Katoch CDS, Chandran VM, Bhattacharyya D, Barthwal MS: Closure of bronchopleural fistula by interventional bronchoscopy using sealants and endobronchial devices. Med J Armed Forces India 2013;69:326-329.

$\checkmark 3$ Takaoka K, Inone S, Ohira S: Central bronchopleural fistulas closed by bronchoscopic injection of absolute ethanol. Chest 2002;122: 374-378.

$\checkmark 4$ Hollaus PH, Lax F, Janakiev D, et al: Endoscopic treatment of postoperative bronchopleural fistula: experience with 45 cases. Ann Thorac Surg 1998;66:923-927.
5 Cardillo G, Carbone L, Carleo F, et al: The rationale for treatment of postresectional bronchopleural fistula: analysis of 52 patients. Ann Thorac Surg 2015;100:251-257.

-6 Fiorelli A, Frongillo E, Santini M: Bronchopleural fistula closed with cellulose patch and fibrin glue. Asian Cardiovasc Thorac Ann 2015;23:880-883.

-7 Ottevaere A, Slabbynck H, Vermeersch P, et al: Use of Amplatzer device for endoscopic closure of large bronchopleural fistula following lobectomy for a stage I squamous cell carcinoma. Case Rep Oncol 2013;6:550-554.
8 Bhat YM, Banerjee S, Barth BA: Tissue adhesives: cyanoacrylate glue and fibrin sealant. Gastrointest Endosc 2013;78:209-215.

9 Scappaticci E, Ardissone F, Ruffini E, et al: Postoperative bronchopleural fistula: endoscopic closure in 12 patients. Ann Thorac Surg 1994;57:119-122.

10 Klotz VL, Gesierich W, Schott-Hildebrand S, et al: Endobronchial closure of bronchopleural fistula using Amplatzer device. J Thorac Dis 2015;7:1478-1482.

11 Dutau H, Breen DP, Carine G, et al: The integrated place of tracheobronchial stents in the multidisciplinary management of large postpneumonectomy fistulas: our experience using a novel customised conical self-expandable metallic stent. Eur J Cardiothorac Surg 2011;39:185-189.
PVA Sponge and Cyanoacrylate Glue in BPF after Lung Cancer 